\title{
Teaching Breast Cancer Screening via Text Messages as Part of Continuing Education for Working Nurses: A Case-control Study
}

\author{
Sadaf Alipour ${ }^{1 *}$, Forouzandeh Jannat ${ }^{2}$, Ladan Hosseini ${ }^{3}$
}

\begin{abstract}
Introduction: Although continuing education is necessary for practicing nurses, it is very difficult to organize traditional classes because of large numbers of nurses and working shifts. Considering the increasing development of mobile electronic learning, we carried out a study to compare effects of the traditional face to face method with mobile learning delivered as text messages by cell phone. Materials and Methods: Sixty female nurses working in our hospital were randomly divided into class and short message service (SMS) groups. Lessons concerning breast cancer screening were prepared as 54 messages and sent in 17 days for the SMS group, while the class group participated in a class held by a university lecturer of breast and cancer surgery. Pre- and post-tests were undertaken for both groups at the same time; a retention test also was performed one month later. For statistical analysis, the paired $\mathbf{T}$ test and the independent sample $\mathbf{T}$ test were used with SPSS software version 16; $p<0.05$ was considered significant. Results: Mean age and mean work experience of participants in class and SMS groups was $35.8 \pm 7.2,9.8 \pm 6.7,35.4 \pm 7.3$, and $11.5 \pm 8.5$, respectively. There was a significant increase in mean score post-tests (compared with pre-tests) in both groups $(\mathbf{p}<0.05)$. Although a better improvement in scores of retention tests was demonstrated in the SMS group, the mean subtraction value of the post- and pretests as well as retention- and pre-tests showed no significant difference between the 2 groups $(p=0.3$ and $p=0.2$, respectively). Conclusions: Our study shows that teaching via SMS may probably replace traditional face to face teaching for continuing education in working nurses. Larger studies are suggested to confirm this.
\end{abstract}

Keywords: Breast cancer screening - education - e-learning - short message service - nurses

Asian Pac J Cancer Prev, 15 (14), 5607-5609

\section{Introduction}

Continuing education has been increasingly considered for nurses in recent years due to extraordinary growth of science and rapidly occurring changes in health care structure as well as in the responsibilities of nursing teams (Griscti and Jacono, 2006). The large number of nurses in hospitals and their working shifts has made troubles for holding courses at particular times and in defined areas for all of them. Holding multiple classes in different subjects would also lead to elevated costs for the hospital or the health system. On the other hand, learning methods with the use of electronic resources are quickly developing and are considered by educational programmers in various conditions. Among mobile learning devices, cell phones are particularly popular because of their nearly unlimited and easy to use accessibility in a mobile setting ( $\mathrm{Lu}$, 2008; Woods et al., 2012). Personal ownership of mobile devices has also augmented in recent decades, and in some settings even their use as an educational aid would not be an inconvenience for the class. As with other categories, emergent mobile technologies are also growingly used by health professionals for teaching purposes (Dearnley et al., 2008).

The aim of this study was to compare the impact of traditional face to face teaching with electronic learning via short message service (SMS) in improving the knowledge of nurses about breast cancer screening as part of continuing education programs in our hospital.

\section{Materials and Methods}

This clinical trial was conducted in arash women's hospital, a teaching hospital affiliated to tehran university of medical sciences. The studied sample consisted of 60 female nurses who were enrolled and randomly divided in two equal groups: group 1 or class group and group 2 or SMS group. The topic of education was breast cancer screening.

First, each participant completed a test including 10 multiple choice questions about breast cancer screening. Ten days later, in group 1 , a university assistant professor of breast and cancer surgery taught the subject of breast cancer screening with traditional face to face method 
by using traditional lecture and very well-organized power point slides. The same lessons were handled in 54 messages and sent as 3 to 4 SMS per day via cell phones to group 2 during 17 days. Ten days after the class of group 1 ( 2 days after the last message in group 2), a posttest containing the same questions as the pre-test was conducted. In order to evaluate the recall knowledge of the participants, the same test was held again one month later (retention test). Pre-, post and retention tests were corrected and scored for each group according to the number of correct answers, scores of the pre-tests were subtracted from the post- and retention tests scores. For statistical analysis, paired T Test and independent sample T Test were used in SPSS software version 16; $\mathrm{p}<0.05$ was considered significant.

\section{Results}

The mean age of the participants in the class and SMS groups was $35.8 \pm 7.2$ and 35.4 \pm 7.3 , respectively. The mean work experience (years practicing as a hospital nurse) did not differ between two groups $(9.8 \pm 6.7$ in control vs. $11.5 \pm 8.5$ in SMS group). The mean pre-test score was $3.6 \pm 1.6$ in group 1 and it rose to $5.9 \pm 1.8$ in the post-test. These values were respectively $4 \pm 1.6$ and $5.8 \pm 2$ in the pre- and post tests of group 2 . As a result, a significant increase in the mean scores was demonstrated between the pre-test and the post-test in both groups $(\mathrm{p}<0.05$.

Thereafter, the subtraction value of the post- and pretests was calculated for each participant, the mean subtraction value was then considered and compared between the 2 groups. The results showed a mean subtraction value of $2.3 \pm 2.2$ for group 1 and $1.7 \pm 2$ for group 2; theses did not differ significantly $(\mathrm{p}=0.3)$. The same process was undertaken for the retention test; pretest scores of every participant were subtracted from the retention test score and the mean calculated in each group. The mean values were higher in group 2, showing a better improvement in scores after 1 month in the SMS group, nevertheless these differences were not significant $(\mathrm{p}=0.2)$.

\section{Discussion}

Breast cancer is the most common female cancer and the second cause of death from cancer in women worldwide. Screening of breast cancer helps in early diagnosis and better control of the disease; physicians and nurses have a key role in patient awareness. Therefore, some studies have assessed level of knowledge of nursing students and nurses about breast cancer and many of them have suggested that continued education about the subject was necessary for them. Sreedharan et al investigated knowledge and practice of breast self exam in 154 nurses working in the United Arab Emirates hospitals via a self-administered structured questionnaire and made out satisfactory results (Sreedharan et al., 2010). Yousuf et al examined general knowledge about breast cancer and its risk factors in 210 Saudi nurses practicing in primary health care centers (Yousuf et al., 2012) while Fotedar et al investigated the knowledge of nurses about breast cancer risk factors and methods of early detection in 457 nurses in a medical college in India (Fotedar et al., 2013); Ozkan et al assessed the level of knowledge as well as beliefs about breast self examination in 113 nursing and midwifery students (Ozkan et al., 2010) and Andsoy et al carried out a study to investigate knowledge of breast, cervical and colorectal cancer screening among 226 working nurses (Andsoy and Gul, 2014). All these researchers concluded that adequate awareness about the subject may be raised in nurses by establishing continuing education programs.

Approaches to medical knowledge, as well as the science itself, are going through constant modifications (Ducut and Fontelo, 2008). There are various teaching methods; the point is to find the most appropriate for each group of learners in different settings. Keat et al carried out an interventional study where they investigated effects of courses and workshops on knowledge about safe practices while working with cytotoxic drugs in nurses. They showed significant benefits of these interventions on nurses knowledge (Keat et al., 2013). Khokhar et al handled training workshops about breast cancer and screening guidelines for 259 nurses. They showed more than $40 \%$ increase in knowledge about screening after the courses (Khokhar, 2012).

In our hospital, continuing education of nurses is achieved by organizing face-to-face classes and studying paper-based material as a pre-set routine. Nevertheless, this is difficult to accomplish because large crowded classes could lessen the motivation and satisfaction of students and limit their interaction with lecturers (Exeter et al., 2010). As well, it is impossible to gather nurses of one or several wards at a time; holding multiple classes after grouping them according to their work shifts also necessitates multiple sessions and will take a long time for the teacher and a great cost for the hospital or supervising university. Another disadvantage of this system is the complexity to meet learning needs of every nurse because of the disparities existing among them. However, in mobile learning, learners have freedom to study according to their own needs and preferences along with the given space and time (Bernard et al., 2004). Advantages of mobile learning methods have induced researchers to use various electronic technologies for educational purposes even in post-graduate levels and for health care practitioners, and a study carried out by Pilcher et al showed that nurses in all ages are eager to learn via several electronic methods (Pilcher and Bedford, 2011). Clay et al assessed whether mobile methods of education could help learning clinical skills by loading data about the physical examination of newborns and infants in iPods held by participants in clinical settings. The questionnaire completed by these at 12 weeks showed that mobile learning was an interesting, time- and place flexible way for gaining knowledge about clinical skills (Clay, 2011). Mazzoleni et al investigated whether a planned online educational program could effectively replace traditional face-to- face methods of teaching for medical staff in hospitals. They showed that electronic learning could not be a substitute for all purposes but was cost-effective for education of large populations of health-related practitioners (Mazzoleni et al., 2012). A systematic review carried out by Lu et al has shown that web-based distance education is effective 
in increasing knowledge and skill performance in nurses (Du et al., 2013).

Nevertheless, the most popular electronic devices are cell phones, and although these can be used for handling web-based learning material, access to internet is not possible everywhere and at every time, especially in developing countries. Mobile phone devices are already known as a well-designed and appropriate media for transferring data between medical staff and patients (Mohammadzadeh et al., 2013); these have been successfully used by Jayakrishnan et al for transmitting health-related knowledge and counseling purposes in a smoking cessation interventional research (Jayakrishnan et al., 2013). Hence, if it could be shown that teaching via SMS had a good impact on knowledge acquisition in health care practitioners, it would be most useful for planning SMS-based continuous education programs.

In order to instruct important tips of the perinatal education program to practicing midwives, Woods et al used SMS sent by cell phone to 2500 of them, and found out that recipients believed messages had a good impact on their knowledge acquisition and were eager to continue with the process (Woods et al., 2012). Alipour et al compared learning effect and learner's satisfaction in paper-based and SMS-based method in doctors practicing as gynecology residents by handling printed material and text messages about breast cancer facts and performing pre- and post tests for both methods. They detected a significantly better effect and higher motivation in the SMS group (Alipour et al., 2012).

In the present study, teaching effects of sending educational material via SMS has been compared with our traditional face to face method in organized classes in working nurses. For ease of comparison, a specific subject which consisted of "advantages, necessity, and method of breast cancer screening" had been considered as the subject of teaching. Results showed that teaching via SMS increased knowledge of nurses to the same level as traditional face to face teaching, and the acquired information was retained for a longer time, although differences were not significant. Even with these parallel results, we believe that the SMS method is superior because it did not need either a specific place (the class) or time (a time out of work shifts, out of home and far from family). As well, messages prepared by the teacher can potentially be sent to a much larger number of nurses whereas the same amount of instruction would need multiple class sessions.

Our study shows that traditional face to face learning may probably be substituted by text messages for continuing education in working nurses. Larger studies are suggested to confirm this.

\section{References}

Alipour S, Moini A, Jafari-Adli S, Gharaie N, Mansouri K (2012). Comparison of teaching about breast cancer via mobile or traditional learning methods in gynecology residents. Asian Pac J Cancer Prev, 13, 4593-5.

Andsoy II, Gul A (2014). Breast, cervix and colorectal cancer knowledge among nurses in turkey. Asian Pac J Cancer Prev, 15, 2267.
DOI:http://dx.doi.org/10.7314/APJCP.2014.15.14.5607

Teaching Breast Cancer Screening to Nurses via Text Messages Bernard RM, Abrami PC, Lou Y, et al (2004). How does distance education compare with classroom instruction? a meta-analysis of the empirical literature. Rev Educ Res, 74, 379-439.

Clay CA (2011). Exploring the use of mobile technologies for the acquisition of clinical skills. Nurse Educ Today, 31, 582-6.

Dearnley C, Haigh J, Fairhall J (2008). Using mobile technologies for assessment and learning in practice settings: A case study. Nurse Educ Pract, 8, 197-204.

Du S, Liu Z, Liu S, et al (2013). Web-based distance learning for nurse education: a systematic review. Int Nurs Rev, 60 , 167-77.

Ducut E, Fontelo P (2008). Mobile devices in health education: Current use and practice. J Comput Higher Educ, 20, 59-68.

Exeter DJ, Ameratunga S, Ratima M, et al (2010). Student engagement in very large classes: the teachers' perspective. Stud High Educ, 35, 761-75.

Fotedar V, Seam RK, Gupta MK, et al (2013). Knowledge of risk factors and early detection methods and practices towards breast cancer among nurses in Indira Gandhi Medical College, Shimla, Himachal Pradesh, India. Asian Pac J Cancer Prev, 14, 117-20.

Griscti O, Jacono J (2006). Effectiveness of continuing education programmes in nursing: literature review. J Adv Nurs, $\mathbf{5 5}$, 449-56.

Jayakrishnan R, Mathew A, Uutela A, Auvinen A, Sebastian $P$ (2013). Multiple approaches and participation rate for a community based smoking cessation intervention trial in rural Kerala, India. Asian Pac J Cancer Prev, 14, 2891-6.

Keat CH, Sooaid NS, Yun CY, Sriraman M (2013). Improving safety-related knowledge, attitude and practices of nurses handling cytotoxic anticancer drug: pharmacists' experience in a general hospital, Malaysia. Asian Pac J Cancer Prev, 14, 69-73.

Khokhar A(2012). Effect of a training programme on knowledge of nurses from a missionary hospital in India regarding breast cancer and its screening. Asian Pac J Cancer Prev, 13, 5985-7.

Lu M (2008). Effectiveness of vocabulary learning via mobile phone. J Comput Assist Lear, 24, 515-25.

Mazzoleni MC, Maugeri C, Rognoni C, Cantoni A, Imbriani M (2012). Is it worth investing in online continuous education for healthcare staff? Stud Health Technol Inform, 180, 939-43.

Mohammadzadeh N, Safdari R, Rahimi A (2013). Cancer care management through a mobile phone health approach: Key considerations. Asian Pac J Cancer Prev, 14, 4961-4.

Ozkan A, Malak AT, Gürkan A, San Turgay A (2010). Do Turkish nursing and midwifery students teach breast selfexamination to their relatives? Asian Pac J Cancer Prev, 11, 1569-73.

Pilcher JW, Bedford L (2011). Willingness and preferences of nurses related to learning with technology. J Nurses Staff Dev, 27, 10-6.

Sreedharan J, Muttappallymyalil J, Venkatramana M, Thomas M (2010). Breast self-examination: knowledge and practice among nurses in United Arab Emirates. Asian Pac J Cancer Prev, 11, 651-4.

Woods D, Attwell A, Ross K, Theron G (2012). Text messages as a learning tool for midwives. S Afr Med J, 102, 100-1.

Yousuf SA, Al Amoudi SM, Nicolas W, Banjar HE, Salem SM (2012). Do Saudi nurses in primary health care centres have breast cancer knowledge to promote breast cancer awareness. Asian Pac J Cancer Prev, 13, 4459-64. 